\title{
Short communication: Economics of sex-biased milk production
}

\author{
J. F. Ettema* ${ }^{1}$ and S. Østergaard‡ \\ *SimHerd A/S, Agro Business Park, Niels Pedersens Alle 2, 8830 Tjele, Denmark \\ †Department of Molecular Biology and Genetics, and \\ ‡Department of Animal Science, Center for Quantitative Genetics and Genomics, Aarhus University, PO Box 50, 8830 Tjele, Denmark
}

\begin{abstract}
In a recent data study using 2.4 million lactations of 1.5 million cows, it was reported that gestation of a female calf in the first parity increases cumulative milk production by approximately $445 \mathrm{~kg}$ over the first 2 lactations. The reported effect in this study is large and remarkable because it has not been found before. To our knowledge, the economic implications of this or any other sex bias have not been studied. The objective of the current study was to quantify the reported influence of fetal sex across lactations by using a simulation model of a dairy herd including youngstock. Two scenarios were evaluated and compared with a scenario in which cows and heifers were exclusively bred with conventional (nonsexed) semen. In the first scenario, sexed semen was used moderately — on $30 \%$ of all heifers and $30 \%$ of the first parity cows. A second scenario was studied in which sexed semen was used intensively - on all heifers and 50\% of the first-parity cows. The simulated proportion of cows giving birth to 2 consecutive heifers increased from $23 \%$ when using exclusively conventional semen up to 31 and $48 \%$ when using sexed semen moderately and intensively, respectively. The proportion of cows having 2 consecutive bulls decreased from $27 \%$ (conventional semen only) to 20 and $8 \%$ when using sexed semen moderately and intensively, respectively. When incorporating the sex bias in the simulation model, the simulated milk yield in the scenario in which sexed semen was used moderately increased by $48 \mathrm{~kg}$ of energy-corrected milk (ECM) per cow/yr, compared with only $36 \mathrm{~kg}$ of ECM when not incorporating the sex bias in the model. For the scenario in which sexed semen was used intensively, milk yield increased by 66 and $99 \mathrm{~kg}$ of ECM when excluding and including the sex bias, respectively. The economic implications of the assumed sex bias were $€ 4.0$ and $€ 9.9$ per cow/yr, in the scenarios in which sexed semen was used moderately and intensively, respectively.
\end{abstract}

Received August 22, 2014.

Accepted October 28, 2014

${ }^{1}$ Corresponding author: je@simherd.com
Key words: sex-biased milk yield, economics, sexed semen

\section{Short Communication}

In a recent study that used records from 1995 to 1999 of 2.38 million lactation records from 1.49 million dairy cows in the United States, it was shown that fetal sex influences the capacity of the mammary gland to synthesize milk during lactation (Hinde et al., 2014). The study found that cows produced more milk following gestation of a female calf compared with a male calf. When studying a subset of the data (113,750 cows), excluding lactations in which bST was used or that were initiated by dystocia, it was found that the sex of the fetus during first gestation influenced milk yield in both the first and second lactations. Cows delivering a female calf at both their first and second calvings produced $445 \mathrm{~kg}$ more milk (305-d basis) during their first and second lactations compared with cows delivering bull calves at first and second calvings. A similar effect $(+441 \mathrm{~kg})$ was found for cows delivering a bull at first calving and a female calf at second calving. Hinde et al. (2014) hypothesized that the mechanism is based on the assumption that fetal-origin hormones translocate via maternal circulation to influence mammary gland development.

The results found by Hinde et al. (2014) are the first to document sex-biased milk production in cows. Subsequently, a study using Canadian data reported a cumulative benefit of having 2 consecutive heifers, compared with male calves, of only $76 \mathrm{~kg}$ (Beavers and Van Doormaal, 2014).

Several other studies have found results that disagree with the findings of Hinde et al. (2014). In those studies, no effect of sex of the fetus was found, but instead a positive effect of birth weight was reported, regardless of the sex of the fetus, on milk yield in the subsequent lactations. Chew et al. (1981) reported that the relationship between calf birth weight and yield was linear and positive for birth weights between 23 and $50 \mathrm{~kg}$. Birth weights $>50 \mathrm{~kg}$ had a negative relationship with milk yield, which can be explained by the higher incidence of dystocia for heavy calves. Chew et al. (1981) 
hypothesized that the positive correlation between fetus weight and higher concentrations of blood estrogen and placental lactogen, important hormones for mammary gland development, play an important role in explaining the mechanism. A curvilinear relationship between birth weights and milk production in subsequent lactations was also reported for both Jersey and Holstein cows by Thatcher et al. (1980). This relationship is in disagreement with the findings of Hinde et al. (2014), because bull calves are typically heavier than heifer calves (Kertz et al., 1997). The findings of Hinde et al. (2014) on the positive relationship between sex of the fetus in the current lactation were not in conflict with the results of Swali and Wathes (2006). That study demonstrated a positive relationship between low calf BW at next calving and milk yield in the current lactation. Swali and Wathes (2006) hypothesized that fetal development competes for nutrients with concurrent milk production.

The commercial availability of sexed semen gives farmers the opportunity to influence the sex of calves and thereby improve the economic performance of their herd (Olynk and Wolf, 2007; Ettema et al., 2011; McCullock et al., 2013). In none of these economic analyses was sex-biased milk production, as found by Hinde et al. (2014), taken into consideration. The current study aimed to quantify the economic importance of the sex-biased milk production for different strategies of using sexed semen. The model used in this study was SimHerd (SimHerd A/S, Tjele, Denmark; Østergaard et al., 2005), a dynamic, stochastic, and mechanistic simulation model of a dairy herd, including youngstock. In the model, the state of an animal is defined by age, parity, lactation stage, a permanent component of milk yield potential, actual milk yield, BW, culling status, reproductive status (estrus and pregnancy), SCC, and disease status. A prediction of the current state is made week by week for each cow and heifer in the herd. The state of the individual animal is updated and production and input consumption of the herd calculated. For this study, the simulation model was parameterized so that the cows' estrus detection rate and conception rate to d 14 after AI were 0.55 and 0.60 , respectively. An additional risk of fetal death, which included early fetal death, was set at 0.13 . First-parity cows with a milk yield higher or lower than the parity-specific median were specified to have an AI period until 330 or 225 DIM, respectively. For greater-parity cows, the AI periods were terminated at 301 and 196 DIM, respectively. The AI periods were initiated $49 \mathrm{~d}$ after calving (voluntary waiting period). A cow not pregnant after the AI period was replaced when a heifer calved and entered the herd and the cow in question was the lowestyielding candidate for voluntary culling. The maximum number of cows in the herd was set at 200. Heifers were sold in the absence of culling candidates and if the cow numbers reached 200. The AI period for heifers was initiated at the age of $454 \mathrm{~d}$ and terminated at $730 \mathrm{~d}$; heifers were culled when not pregnant at this age. The heifer conception rate for conventional semen was set at 0.60 and the estrus detection rate was assumed to be 0.60 . The proportion of the conception rate obtained with sexed semen was set at 0.80 (DeJarnette et al. 2007) relative to that of conventional semen. Heifers pregnant with sexed semen were not sold; instead, the lowest-yielding cow, whether or not her insemination period was terminated, was culled. The proportion of females born from sexed semen and conventional semen was 90 and 48\%, respectively (Borchersen and Peacock, 2009). The general assumptions on all other herd management parameters made in this study were representative for a 200-cow Danish dairy herd with Holstein-Friesian cattle. A full description of the parameterization of the SimHerd model can be found in Kristensen et al. (2008).

The SimHerd model was used to simulate 3 strategies of sexed semen use. In the default scenario (DEF), conventional semen was used on all heifers and all cows. In the second scenario, sexed semen was used on $30 \%$ of the heifers and $30 \%$ of the first parity cows $(\mathbf{3 0}-\mathbf{3 0 \%})$. Heifers and cows were bred with sexed semen up to 2 times; thereafter, they were inseminated with conventional semen until pregnancy or their insemination period was terminated. The third scenario was identical to the second scenario except that sexed semen was used on all heifers and on $50 \%$ of first-parity cows (100-50\%). In the $30-30 \%$ and $100-50 \%$ scenarios, beef semen was used on 33 and $66 \%$ of the lactating cows, respectively. This was done to limit the size of the youngstock herd. Using sexed semen extensively, combined with the decision to keep all heifers pregnant with sexed semen, would result in a very high replacement rate and surplus of youngstock. By using the aforementioned proportion of beef semen, all scenarios had the same replacement rate of $31 \%$, which enabled a fair comparison between scenarios. Beef semen and sexed semen were used on the lowest-yielding and highest-yielding cows, respectively. Sexed semen was used on heifers with the highest breeding value for milk yield, as done in Ettema et al. (2011). Each scenario was simulated over a $10-y r$ period and replicated 500 times. Through test simulations, we previously found that, after simulations of $5 \mathrm{yr}$, the effect of the initial herd was diminished. The initial herd was generated randomly; therefore, the herd could contain, by chance, a large number of first-parity cows. If sexed semen were used on first-parity cows, the milk yield would be higher in the second simulation year, partly because 
the simulated herd has many second-parity cows in the second simulation year. To address the effect of the scenarios rather than the effect of the initial herd, we used average annual results from the last $5 \mathrm{yr}$ of each replicate. The prices applied in this study included $€ 80$, $€ 87$, and €175 for purebred Holstein bull calves, crossbred-heifer calves, and crossbred bull calves sold at 14 $\mathrm{d}$, respectively. The prices additionally included $€ 1,275$ for springing heifers, €0.41 per $\mathrm{kg}$ of $\mathrm{ECM}$, and $€ 15$, $€ 31$, and $€ 11$ per dose of normal semen, sexed semen, and beef semen, respectively. Net return was calculated as the sales income minus the variable costs for cows and additional youngstock. The results from Hinde et al. (2014) were used as follows. Compared with giving birth to consecutive males (MM), 305-d milk yield was assumed to be 186 and $260 \mathrm{~kg}$ higher during the first $305 \mathrm{~d}$ of the first and second lactations, respectively, if the sex of both the first- and second-born calf was female (FF). For cows giving birth to a male and a female at first and second calving (MF), respectively, milk yield was 108 and $194 \mathrm{~kg}$ higher compared with MM. Milk yield was assumed to be 172 and $269 \mathrm{~kg}$ higher in first and second lactations, respectively, if the cow's first calf was female and her second calf was male (FM). Rather than using the above stated quantities of milk, a proportional increase was used compared with $305-\mathrm{d}$ milk yield of MM in first lactation $(7,768 \mathrm{~kg})$ and second lactation $(8,345 \mathrm{~kg})$. In Figure 1, the sex distribution of the first- and second-born calves is presented for the 3 scenarios.

When using sexed semen extensively, $48 \%$ of the cows had 2 consecutive females and only $8 \%$ of the cows had consecutive males. In DEF, milk yield and net return per cow/yr were $9,684 \mathrm{~kg}$ of ECM and $€ 2,401$, respectively. Figures 2 and 3 present the differences in milk yield per cow/yr in ECM and net return per cow/yr $(€)$ for the 2 sexed semen scenarios, compared with DEF.

Using sexed semen increased milk yield and net return when sex bias was not included. This is because genetically superior and inferior cows are bred with sexed semen and beef semen, respectively, which results in a higher milk yield from the next generation of cows in the herd. However, the simulated differences relative to the DEF scenario should be considered an underestimation of the full effect, because the simulated results represent simulation years 6 to 10. Earlier studies with SimHerd have shown that the full effect on genetic progress in scenarios using sexed semen is realized after 15 yr (Ettema et al., 2011). This underestimation, however, is made when simulating the scenarios with and without including the sex bias. The economic performance of these scenarios furthermore depends greatly on the costs of the crossbred calves, springing heifers, and semen.

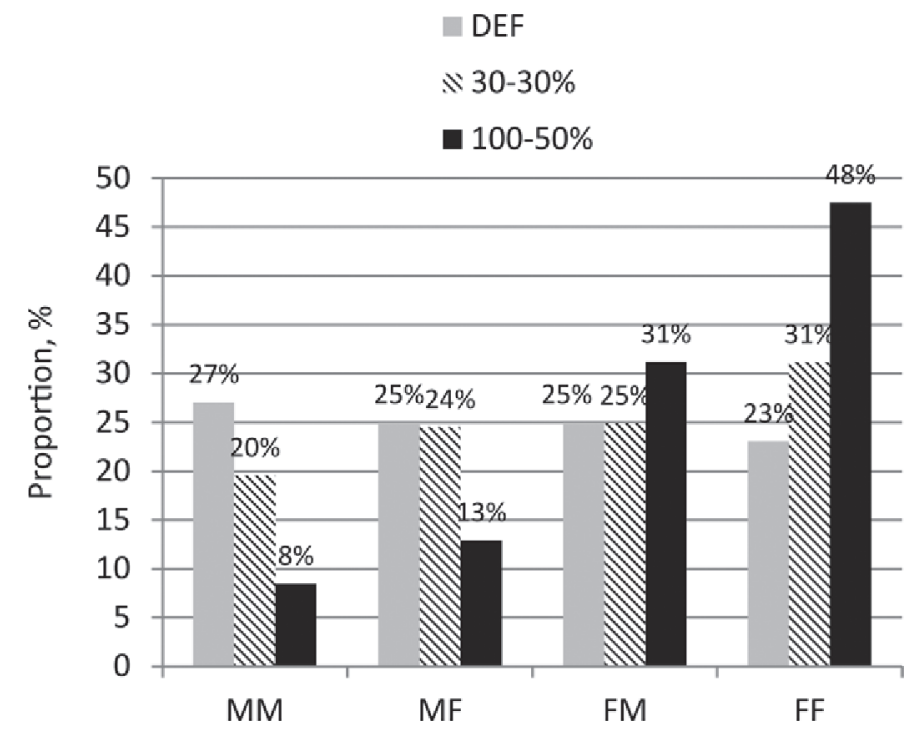

Figure 1. Proportion of cows giving birth at first and second calvings to calves of different sex $(\mathrm{M}=$ male, $\mathrm{F}=$ female $)$ for different strategies of sexed semen use [where 30-30\% (100-50\%) = scenario in which sexed semen is used on $30 \%(100 \%)$ of the heifers and $30 \%$ $(50 \%)$ of the cows] and a default strategy in which no sexed semen is used (DEF).

In this study, we quantified the economic importance of the sex-biased milk production reported by Hinde et al. (2014). Our results show that the milk yield increase, as an effect of the assumed sex bias, was estimated at $33 \mathrm{~kg}$ of ECM per cow/yr in the 100-50\% scenario. The economic implications of the assumed sex bias were $€ 9.9$ per cow/yr (€1,980 for a 200 -cow herd) in the $100-50 \%$ scenario. When comparing the

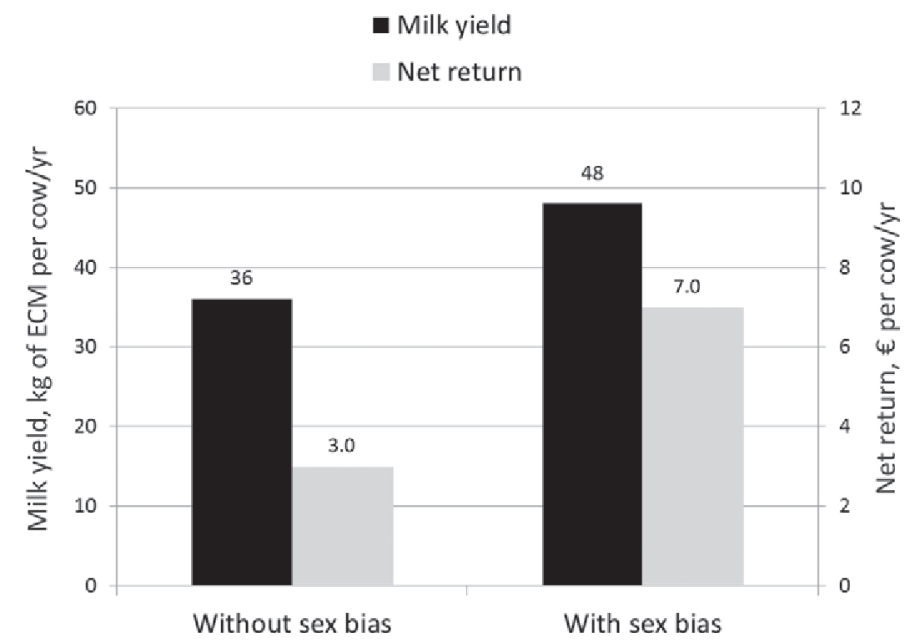

Figure 2. Simulated differences in milk yield (kg of ECM per cow/ yr and net return, $€$ per cow/yr) for the scenario in which sexed semen is used on $30 \%$ of the heifers and $30 \%$ of the cows, compared with the default scenario. Results are shown for the simulation in which the sex bias was included (with sex bias) and excluded (without sex bias). 


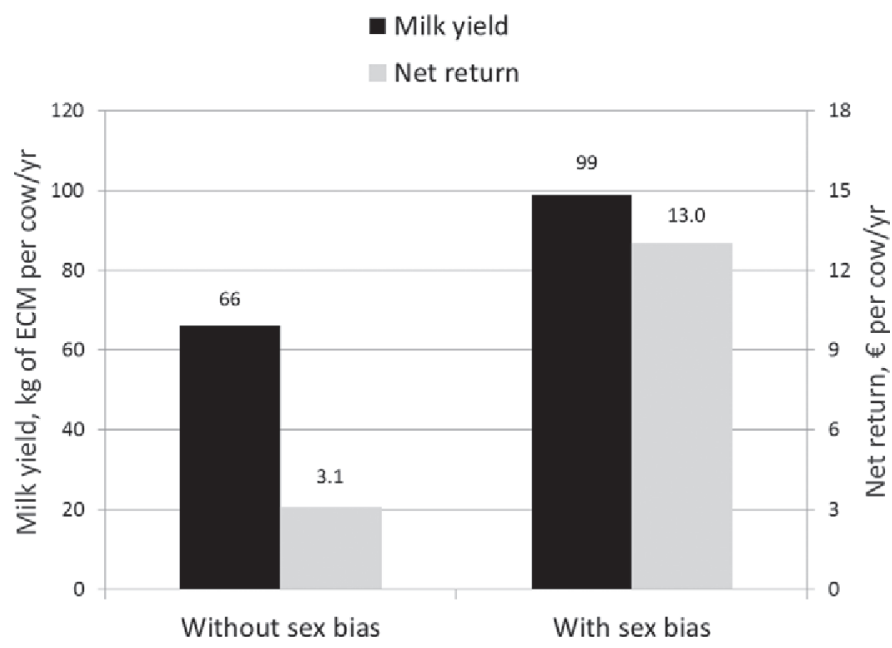

Figure 3. Simulated differences in milk yield (kg of ECM per cow/ yr and net return, $€$ per cow/yr) for the scenario in which sexed semen is used on $100 \%$ of the heifers and $50 \%$ of the cows, compared with the default scenario. Results are shown for the simulation in which the sex bias was included (with sex bias) and excluded (without sex bias).

results for $30-30 \%$ and $100-50 \%$, it can be seen that the importance of the assumed sex bias decreases with the intensity of using sexed semen.

Hinde et al. (2014) also reported the effects of sex of the fetus in third and later gestations on the subsequent lactations. The economic importance of this effect was not explored in our simulation experiment where only heifers and first-parity cows were inseminated with sexed semen, as is common practice in Denmark. The proportion of cows having heifer calves could have been increased even more in our simulation study. However, the decision variables were set in a way that represented a scenario in which all heifers pregnant with sexed semen were kept in the herd. If more sexed semen had been used and on greater-parity cows, heifers pregnant with sexed semen should have been sold or more heifers should have been used for replacement. Both options were undesirable. For obvious reasons, it is not possible to benefit from the sex bias when heifers pregnant with sexed semen are sold and have their calf in another herd. Increasing the replacement rate would have made the comparison between sexed semen scenarios more difficult. If the decision is made to increase the replacement rate and have more heifers calving in the herd, the benefits of the sex bias can be expected to be larger. Whether the overall net return increases because of increasing replacement rate is another question and not a subject of interest in the current study.
Finally, it should be stressed that the simulated results depend on the evidence incorporated into the model. The simulated change in milk yield in the sexed semen scenarios would have been lower if a negative correlation between fetus weight and milk yield (i.e., as reported by Thatcher et al., 1980, and Chew et al., 1981) had been incorporated into the model.

\section{ACKNOWLEDGMENTS}

The research leading to these results has received funding from the European Union Seventh Framework Program (FP7/2007-2013) under the grant agreement n³11776.

\section{REFERENCES}

Beavers, L., and B. Van Doormaal. 2014. Is sex-biased milk production a real thing? Canadian Dairy Network. Information articles. Accessed Nov. 17, 2014. http://www.cdn.ca/document.php?id=348.

Borchersen, S., and M. Peacock. 2009. Danish A.I. field data with sexed semen. Theriogenology 71:59-63.

Chew, B. P., L. C. Maier, J. K. Hillers, and A. S. Hodgson. 1981. Relationship between calf birth weight and dam's subsequent 200- and 305-day yields of milk, fat, and total solids in Holsteins. J. Dairy Sci. 64:2401-2408.

DeJarnette, J. M., R. L. Nebel, J. Meek, J. Wells, and C. E. Marshall. 2007. Commercial application of sex-sorted semen in Holstein heifers. J. Dairy Sci. 90(Suppl. 1):228. (Abstr.)

Ettema, J. F., S. Østergaard, and M. K. Sørensen. 2011. Effect of including milk yield on evaluating the use of sexed semen and other reproduction strategies in a dairy herd. Animal 5:1887-1897.

Hinde, K., A. J. Carpenter, J. S. Clay, and B. J. Bradford. 2014. Holsteins favor heifers, not bulls: Biased milk production programmed during pregnancy as a function of fetal sex. PLoS ONE 9:e86169. http://dx.doi.org/10.1371/journal.pone.0086169.

Kertz, A. F., L. F. Reutzel, B. A. Barton, and R. L. Ely. 1997. Body weight, body condition score, and wither height of prepartum Holstein cows and birth weight and sex of calves by parity: A database and summary. J. Dairy Sci. 80:525-529.

Kristensen, E., S. Østergaard, M. A. Krogh, and C. Enevoldsen. 2008 Technical indicators of financial performance in the dairy herd. J. Dairy Sci. 91:620-631.

McCullock, K., D. L. K. Hoag, J. Parsons, M. Lacy, G. E. Seidel Jr., and W. Wailes. 2013. Factors affecting economics of using sexed semen in dairy cattle. J. Dairy Sci. 96:6366-6377.

Olynk, N. J., and C. A. Wolf. 2007. Expected net present value of pure and mixed sexed semen artificial insemination strategies in dairy heifers. J. Dairy Sci. 90:2569-2576.

Østergaard, S., M. G. G. Chagunda, N. C. Friggens, T. W. Bennedsgaard, and I. C. Klaas. 2005. A stochastic model simulating pathogen-specific mastitis control in a dairy herd. J. Dairy Sci. 88:4243-4257.

Swali, A., and D. C. Wathes. 2006. Influence of the dam and sire on size at birth and subsequent growth, milk production and fertility in dairy heifers. Theriogenology 66:1173-1184.

Thatcher, W. W., C. J. Wilcox, R. J. Collier, D. S. Eley, and H. H. Head. 1980. Bovine conceptus-maternal interactions during the pre- and postpartum periods. J. Dairy Sci. 63:1530-1540. 